\title{
First-Line Antiretroviral Regimen Failure and Determinants in an Urban HIV Clinic at Phramongkutklao Hospital, Bangkok, Thailand: 20 Years Experience
}

HIVIAIDS - Research and Palliative Care

\author{
Worapong Nasomsong (D) \\ Kwonchit Phokaphol \\ Dhitiwat Changpradub (ID \\ Division of Infectious Diseases, \\ Department of Internal Medicine, \\ Phramongkutklao Hospital, Bangkok, \\ Thailand
}

\begin{abstract}
Purpose: HIV treatment involves antiretroviral therapy (ART) endeavoring to suppress viral load to an undetectable level. Virologic failure occurs when ART fails to suppress and sustain an individual's viral load to less than 200 copies $/ \mathrm{mL}$ after 6 months of therapy. In Thailand, the data among first-line antiretroviral regimen failure and determinants remains limited, especially in urban HIV clinics. We aimed to demonstrate factors of first-line antiretroviral regimen failures in an urban HIV/AIDS clinic at Phramongkutklao Hospital.
\end{abstract}

Patients and Methods: A nested case control 1:4 study was conducted. Data were collected from the electronic patient database among naïve people living with HIV/AIDS (PLWHA), aged $\geq 18$ years and receiving ART continuously for at least 2 years at Phramongkutklao Hospital from 1 January 2000 to 31 December 2019. Multiple logistic regression was used to identify the determinants of virologic failure. Adjusted HRs (AHRs) with 95\% CIs were used to declare statistical significance.

Results: Of 200 PLWHA included in the study, 40 participants experienced HIV virologic failure. The median time after starting ART to virologic failure was 24 months (IQR 7-96.0). Univariate and multivariate analysis showed significant factors affecting first-line antiretroviral regimen failure included being female (37.5 vs 26.88\%, adjusted odds ratio 5.08 [1.05-24.6, p-value 0.043], age $\leq 40$ yr. (62.5 vs $49.6 \%$, adjusted odds ratio 4.59 [1.47-14.37], p-value 0.009), CD4+count $\leq 200$ cell $/ \mu \mathrm{L}$ ( 77.5 vs $52.5 \%$, adjusted odds ratio 4.83 [1.28-18.9], p value 0.02 ), tuberculosis ( 42.5 vs $7.5 \%$, adjusted odds ratio 8.66 [2.37-31.56], $\mathrm{p}$ value $<0.001$ ) and initiation of ART at CD4+ count $<350$ cell $/ \mu \mathrm{L}$ ( 72.5 vs $48.13 \%$, adjusted odds ratio 31.36 [6.51-151.22], p value $<0.001$ ). Estimated prevalence of virologic failure in Phramongkutklao Hospital was 5.34\%.

Conclusion: Our study revealed factors favoring virologic failure included being female, younger age, CD4+ count $<200$ cells $/ \mu \mathrm{L}$, tuberculosis and initiation of ART at CD4+ count $<350$ cell $/ \mu \mathrm{L}$. Multidisciplinary HIV comprehensive care teams should encourage patient adherence and support patients along HIV continuum of care to prevent virologic failure and drug resistance, especially among patients initiating ART at low CD4+ count and tuberculosis co-infection.

Keywords: first-line antiretroviral regimen failure, HIV/AIDS, medical adherence, Thailand, urban HIV clinic

\section{Introduction}

HIV treatment involves antiretroviral therapy (ART), combining daily medications to inhibit the virus from replicating. The main goal of HIV treatment is to reduce a person's viral load to an undetectable level. Durable viral suppression improves
Correspondence: Dhitiwat Changpradub of Internal Medicine, Phramongkutklao Hospital, 317 Ratchavithi Road, Ratchadhevi, Bangkok, 10400, Thailand

Tel +6627639337

Email dhitiwat@yahoo.com 
immune function and overall quality of life, lowers the risk of AIDS-defining and non-AIDS-defining complications, reduces the risk of HIV transmission, and allows people living with HIV/AIDS (PLWHA) to maximize their lifespan approaching that of individuals without HIV. ${ }^{1}$ The early marker for treatment failure is virologic failure. Suboptimal adherence and drug intolerance/toxicity are key contributors to virologic failure and regimen discontinuations. $^{2,3}$ Furthermore, the presence of preexisting (transmitted) HIV with drug resistance may also lead to virologic failure. ${ }^{4}$ Since 2014 , Thailand's national guidelines on HIV/AIDS treatment and prevention recommended initiating ART among all people living with HIV/ AIDS (PLWHA) regardless of level of CD4+ count and all PLWHA in Thailand are able to access ART. The antiretroviral (ARV) regimens commonly used in Thailand include nonnucleoside reverse transcriptase inhibitor (NNRTI) based; nevirapine (NVP), efavirenz (EFV), rilpivirine (RPV) or protease inhibitor (PI) based; lopinavir/ ritonavir (LPV/r) and atazanavir/ritonavir (ATA/r). ${ }^{5,6}$ Principal factors involving first-line antiretroviral regimen failure include poor adherence to medication, younger age, lower baseline CD4+ count and higher baseline viral load. ${ }^{7,8}$ Regarding the incidence of first-line antiretroviral regimen failure ranging from 4.1 to $24.6 \%,{ }^{7,9,10}$ the diversity depended on different geographic areas and the study settings. One study from a university hospital in northern Thailand revealed the incidence of virologic failure was $9.6 \%$ that might have been affected by poor adherence, older age and low baseline CD4+ count. ${ }^{11}$ To date, the data among first-line antiretroviral regimen failure and determinants in Thailand remains limited especially in urban HIV clinics. We aimed to determine factors of first-line antiretroviral regimen failure in an urban HIV/AIDS clinic at Phramongkutklao Hospital to improve treatment strategies.

\section{Materials and Methods}

\section{Study Setting and Design}

A nested case control study was conducted. Data were collected from the electronic patient database from January 2000 to December 2019 in Phramongkutklao Hospital, a 1200-bed teaching hospital of Phramongkutklao College of Medicine, Royal Thai Army, Bangkok, Thailand. The data included sex, age, mode of HIV transmission, antiretroviral regimens, opportunistic infections or tuberculosis (TB) before ART, hepatitis $\mathrm{C}$ virus infection, hepatitis $B$ virus infection, underlying diseases, duration of virologic failure after ART initiation and viral load level at time of virologic failure. Inclusion criteria of participants in both case and control groups were naïve PLWHA, aged $\geq 18$ years old and continuously on ART at Phramongkutklao Hospital $\geq 2$ years. Participants in the virologic failure group were defined as having two consecutive plasma HIV1 viral loads after 6 months of ART $>1000$ copies $/ \mathrm{mL}$, while those in the control group were defined as having plasma HIV-1 viral load after 6 months of ART $<50$ copies/mL. (Supplementary Appendix)

In Thailand, the cumulative incidence of HIV virologic failure was $9.6 \%{ }^{11}$ The preliminary investigation showed 40 virologic failures from 1292 patient's record files. To minimize statistical error, a study of all subjects should be conducted using a nested case control of 1:4. Hence, the sample size of the case group was 40, and that of the control group was 160 . The study protocol followed the guidelines of the Declaration of Helsinki and ethics approval was obtained from the Institutional Review Board, Royal Thai Army Department (reference ID: R015h/62_Exp). Informed consent was waived because of unidentified patient data. All study-related information will be stored securely at the study site with confidentiality and anonymity.

\section{Definitions}

Virologic failure is defined as a plasma viral load above 1000 copies/mL based on 2 consecutive viral load measurements after 3 months with adherence support. ${ }^{12}$

Good adherence was defined as patients taking antiretroviral drug on time, regularly $\geq 95 \%$, while $<95 \%$ was categorized as poor adherence. ${ }^{2}$

The definition of good adherence in this study was assumed from medical records for patients that missed no appointments and continued ARV drugs as described for good adherence.

\section{Statistical Analysis}

Expected parameters affecting virologic failure were analyzed using the independent $t$-test for continuous data, MannWhitney U-test for continuous data without normal distribution and Chi-square or Fisher's exact test for discrete data. Significant data from multivariate analysis $(\mathrm{p}<0.05)$ was analyzed for covariates using multiple logistic regression. All statistical analyses were obtained using STATA/MP12 Software.

\section{Results}

From January 2000 to December 2019, 1292 HIV-positive patients were treated with ART and followed up at 
Phramongkutklao Hospital. Virologic failure occurred among 69 patients; however, 29 patients were excluded due to treatment experienced, referral from other hospitals and loss to follow up. From our nested case control study, 200 participants met eligible criteria (40 participants in the virologic failure group, 160 participants in the virologic suppressed group) (Figure 1). The characteristics of cases and controls are described in Table 1. The majority of participants in either virologic failure or virologic suppressed groups were male and heterosexual. The median CD4+count at presentation was significantly lower in the virologic failure group (98 cell/ $\mu \mathrm{L}$ : [IQR $31-178.5]$ vs 186 cell $/ \mu \mathrm{L}$ [IQR 52.3-329], p-value 0.014). The number of participants initiating ART at CD4+ count less than 350 cell $/ \mu \mathrm{L}$ was significantly higher in the virologic failure group (77 vs 29\%, p-value 0.006). According to ART regimens, the proportion of PI-based regimens in the virologic failure group were significantly higher (20 vs $4.38 \%$, p-value 0.006$)$. Only one half of participants $(57.5 \%)$ in the virologic failure group had a currently undetectable HIV viral load. TB and pneumocystis pneumonia were the 2 most common opportunistic infections and in higher proportions in the virologic failure group (Figure 2). In the virologic failure group, the median time after ART initiation to virologic failure was 24 months (IQR 7-96). Annually median of CD4 + count, after 10 years longitudinal followup in the virologic suppressed group tended to be higher than that in the virologic failure group as shown in Figure 3.

\section{Adherence}

Most participants in the virologic failure group exhibited poor adherence. The rest (32.5\%) showed good adherence in the virologic failure group, while $100 \%$ good adherence was observed in the control group.

\section{Factors of First-Line Antiretroviral Regimen Failure}

According to univariate and multivariate analysis, the significant factors of first-line antiretroviral regimen failures were: being female (37.5 vs $26.88 \%$, adjusted odds ratio 5.08 [1.05-24.6], p-value 0.043), age $\leq 40$ yr. (62.5 vs $49.6 \%$, adjusted odds ratio 4.59 [1.47-14.37], p-value $0.009)$, CD4+ count $\leq 200$ cell $/ \mu \mathrm{L}$ (77.5 vs $52.5 \%$, adjusted odds ratio 4.83 [1.28-18.9], p value 0.02 ), TB (42.5 vs $7.5 \%$, adjusted odds ratio 8.66 [2.37-31.56], p value $<0.001$ ) and initiation of ART at CD4+ count $\leq 350$ cell $/ \mu \mathrm{L}(72.5$ vs $48.13 \%$, adjusted odds ratio 31.36 [6.51-151.22], p-value <0.001) (Table 2).

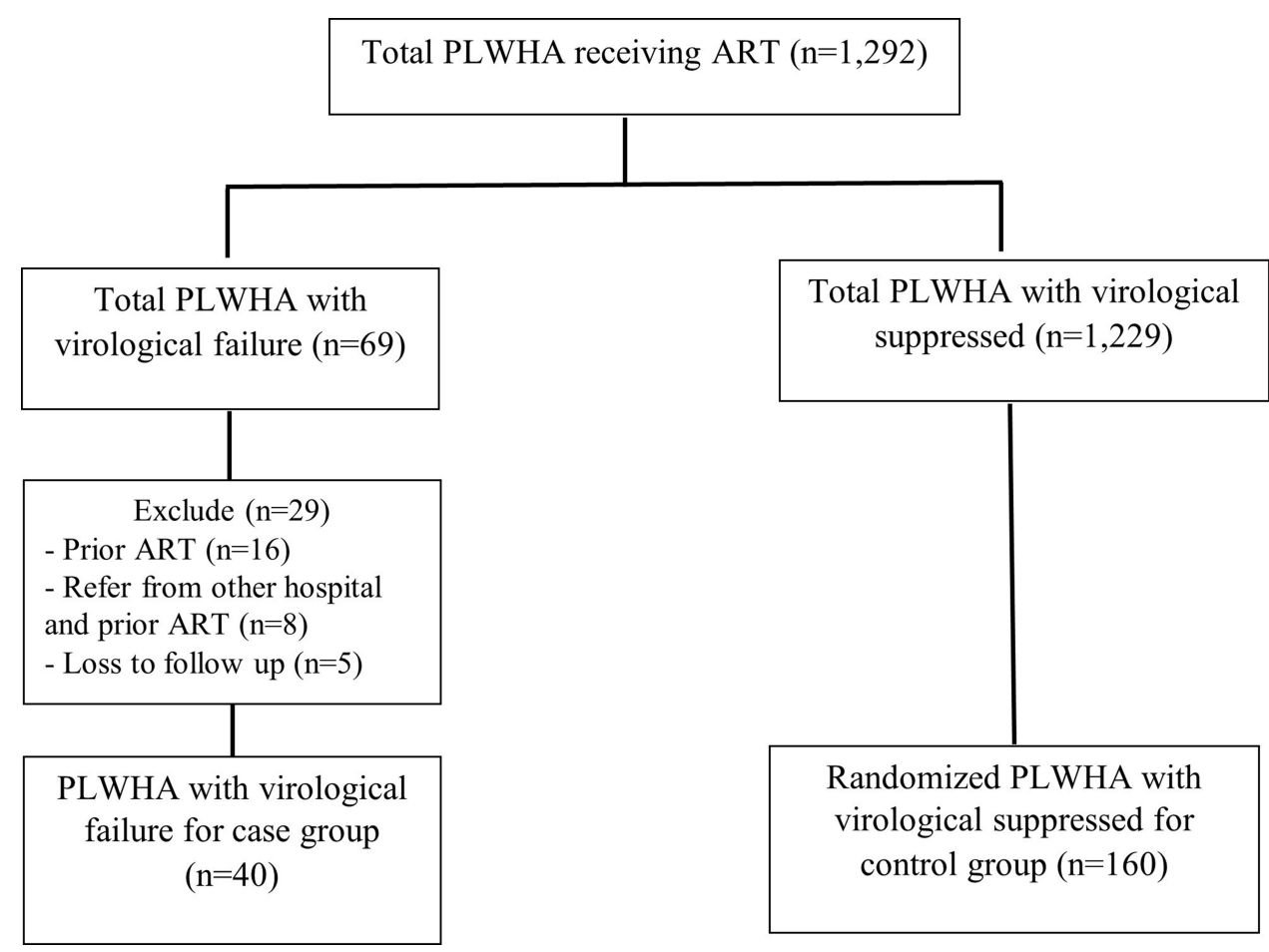

Figure I Participants' enrollment. 
Table I Baseline Characteristics in Virologic Failure and Virologic Suppressed Participants

\begin{tabular}{|c|c|c|c|}
\hline & $\begin{array}{l}\text { Virologic } \\
\text { Failure (\%) } \\
(n=40)\end{array}$ & $\begin{array}{l}\text { Virologic Suppressed (\%) } \\
\qquad(n=160)\end{array}$ & p-value \\
\hline $\begin{array}{l}\text { Sex } \\
\text { Male } \\
\text { Female }\end{array}$ & $\begin{array}{l}25(62.5) \\
15(37.5)\end{array}$ & $\begin{array}{l}117(73.13) \\
43(26.88)\end{array}$ & 0.185 \\
\hline $\begin{array}{l}\text { Age - yrs. } \\
\text { Mean } \pm S D \text { (years) } \\
\leq 40 \text { yrs. } \\
>40 \text { yrs. }\end{array}$ & $\begin{array}{c}38.62 \pm 11.04 \\
25(62.5) \\
15(37.5)\end{array}$ & $\begin{array}{c}41.19 \pm 11.79 \\
78(49.6) \\
82(50.4)\end{array}$ & $\begin{array}{l}0.214 \\
0.128\end{array}$ \\
\hline $\begin{array}{l}\text { Underlying disease } \\
\text { Diabetes Mellitus } \\
\text { Chronic kidney disease }\end{array}$ & $\begin{array}{l}- \\
-\end{array}$ & $\begin{array}{l}3(1.88) \\
\mathrm{I}(0.63)\end{array}$ & $\begin{array}{l}1.0 \\
1.0\end{array}$ \\
\hline $\begin{array}{l}\text { Marriage Status } \\
\text { Married } \\
\text { Single }\end{array}$ & $\begin{array}{l}21(52.5) \\
19(47.5)\end{array}$ & $\begin{array}{l}82(51.25) \\
78(48.7)\end{array}$ & 0.887 \\
\hline $\begin{array}{l}\text { Occupation } \\
\text { Government officer } \\
\text { Employee } \\
\text { Businessman } \\
\text { Other }\end{array}$ & $\begin{array}{c}21(52.5) \\
8(20) \\
1(2.5) \\
10(25)\end{array}$ & $\begin{array}{c}85(53.13) \\
41(25.62) \\
15(9.38) \\
19(11.8)\end{array}$ & 0.106 \\
\hline Start ART at CD4+ $<350$ cell/ $\mu \mathrm{L}$ & $29(72.5)$ & $77(48.13)$ & 0.006 \\
\hline $\begin{array}{l}\text { Mode of HIV transmission } \\
\text { Heterosexual } \\
\text { MSM }\end{array}$ & $\begin{array}{c}36(90) \\
4(10)\end{array}$ & $\begin{array}{l}141(88.3) \\
19(11.8)\end{array}$ & 0.319 \\
\hline $\begin{array}{l}\text { ART regimens } \\
\text { NNRTI based } \\
\text { PI based } \\
\text { Integrase based }\end{array}$ & $\begin{array}{c}32(80.0) \\
8(20.0) \\
-\end{array}$ & $\begin{array}{l}\text { I5I (94.38) } \\
7(4.38) \\
2(1.25)\end{array}$ & 0.006 \\
\hline $\begin{array}{l}\text { CD4+ count (cells/ } \mu \mathrm{L}) \\
\text { Median }(\mathrm{IQR}) \\
\leq 200 \text { cells } / \mu \mathrm{L}\end{array}$ & $\begin{array}{c}98(31-178.5) \\
31(77.5)\end{array}$ & $\begin{array}{c}186(52.5-329) \\
84(52.5)\end{array}$ & $\begin{array}{l}0.014 \\
0.004\end{array}$ \\
\hline Single combination pill as initial regimen & $7(17.5)$ & $33(20.63)$ & 0.659 \\
\hline Duration after initiation to virological failure [Median (IQR)] & - & $24(7-96)$ & - \\
\hline Good adherence & $13(22.5)$ & $160(100)$ & $<0.001$ \\
\hline Current undetectable HIV viral load & $23(57.5)$ & $160(100)$ & $<0.001$ \\
\hline $\begin{array}{l}\text { Opportunistic disease } \\
\text { PCP } \\
\text { Cryptococcosis } \\
\text { Tuberculosis } \\
\text { Malignancy } \\
\text { Others }\end{array}$ & $\begin{array}{l}28(70) \\
9(22.5) \\
2(5.0) \\
16(40) \\
1(2.5) \\
2(5.0)\end{array}$ & $\begin{array}{l}43(26.9) \\
17(10.63) \\
6(3.75) \\
12(7.5) \\
1(0.63) \\
10(8.3)\end{array}$ & $\begin{array}{c}<0.001 \\
0.046 \\
0.662 \\
0.001 \\
0.36 \\
0.49\end{array}$ \\
\hline AIDS defining illness prior ART & $17(42.5)$ & $33(20.5)$ & 0.005 \\
\hline
\end{tabular}

Abbreviations: AIDS, acquired immunodeficiency syndrome; ART, antiretroviral therapy; HIV, The human immunodeficiency viruses; MSM, men who have sex with men; NNRTI, non-nucleoside reverse transcriptase inhibitor; PCP, pneumocystis pneumonia; PI, protease inhibitor. 


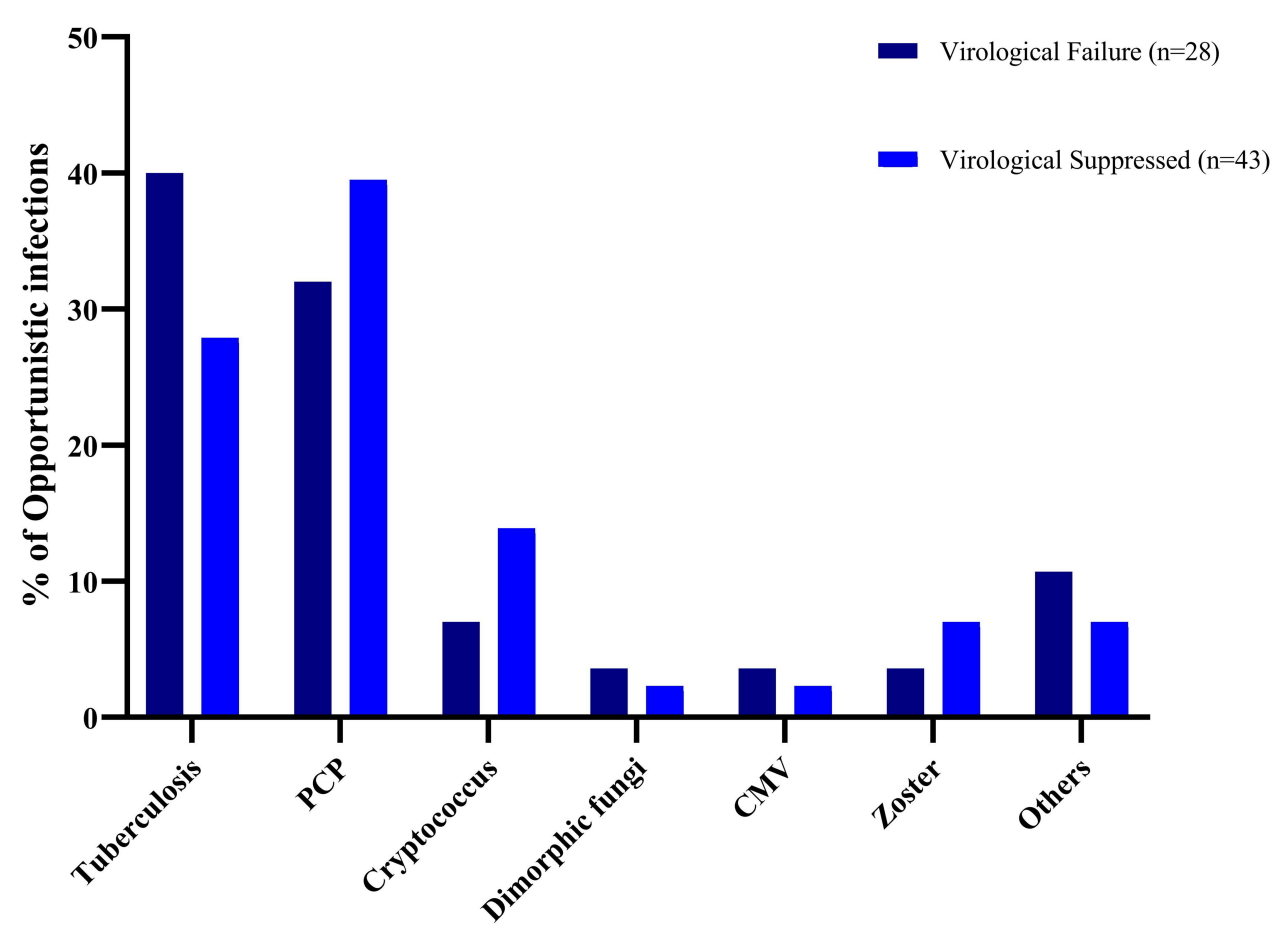

Figure 2 Proportion of opportunistic infections stratified by virologic failure and virologic suppressed group. Abbreviations: CMV, cytomegalovirus; $\mathrm{PCP}$, pneumocystis pneumonia.

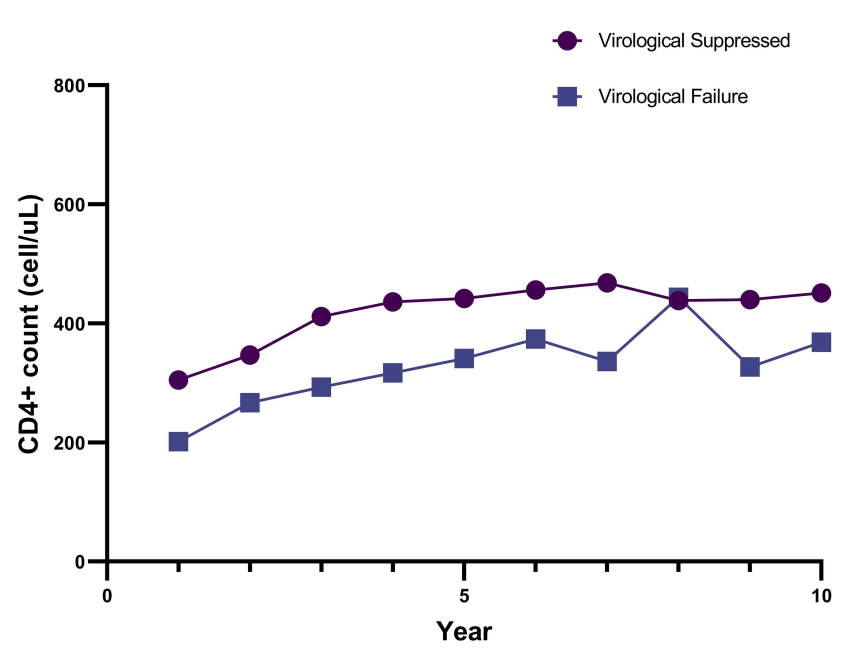

Figure 3 Median CD4+ count in virologic failure and virologic suppressed groups during the 10-year follow-up.

\section{Prevalence of HIV Virologic Failure in Phramongkutklao Hospital}

From January 2000 to December 2019, 1292 HIV-positive patients were treated with ART and followed-up at Phramongkutklao Hospital. Sixty-nine patients presented virologic failure, and the estimated prevalence of virologic failure in Phramongkutklao Hospital was 5.34\%.

\section{Genotypic Resistance Profiles}

Among subjects in the virologic failure group showing good adherence, 4 participants presented virologic failure within 6 months of ART initiation despite good adherence, indicating pretreatment HIV drug resistance (PDR) (Supplementary Appendix). The majority of HIV genotypic resistance in PDR comprised NRTI and NNRTI resistance.

Nine participants in this group developed acquired HIV drug resistance irrespective of good adherence, and 2 cases were suspected to have received the drug resistant virus from their partners. However, the determination of acquired HIV drug resistance was not described in the other 7 cases.

In our cohort, the most common NRTI-associated mutations were M184V followed by K65R, while K103N was the most common NRTI-associated mutation.

\section{Discussion}

Globally, UNAIDS endeavored to have $90 \%$ of people on ART and virally suppressed by 2030 , and as a result, HIV treatment failure would be prevented ${ }^{13}$ by implementing recommended strategies worldwide. These include improving ART adherence, taking medication based on 
Table 2 Univariable and Multivariable Analysis of the Factors of the First-Line Antiretroviral Regimen Failures

\begin{tabular}{|c|c|c|c|c|c|c|}
\hline & $\begin{array}{c}\text { Virologic } \\
\text { Failure (\%) } \\
(n=40)\end{array}$ & $\begin{array}{c}\text { Virologic } \\
\text { Suppressed (\%) } \\
(n=160)\end{array}$ & OR crude $(95 \% \mathrm{Cl})$ & p-value & OR $_{\text {adjusted }}(95 \% \mathrm{Cl})$ & p-value \\
\hline Female & $15(37.50)$ & $43(26.88)$ & $1.63(0.79-3.39)$ & 0.188 & $5.08(1.05-24.6)$ & 0.043 \\
\hline Age $\leq 40$ yrs. & $25(62.50)$ & $78(49.6)$ & $1.73(0.85-3.53)$ & 0.131 & $4.59(1.47-14.37)$ & 0.009 \\
\hline CD4+ count $\leq 200$ cells $/ \mu \mathrm{L}$ & $31(77.50)$ & $84(52.50)$ & $3.12(1.39-6.97)$ & 0.006 & $4.83(1.28-18.9)$ & 0.020 \\
\hline $\mathrm{PCP}$ & $9(22.50)$ & $17(10.63)$ & $2.44(1.00-5.99)$ & 0.051 & $3.58(0.58-22.17)$ & 0.170 \\
\hline Tuberculosis & $17(42.5)$ & $12(7.50)$ & $9.12(3.86-21.54)$ & $<0.001$ & $8.66(2.37-31.56)$ & $<0.001$ \\
\hline Pls vs NNRTI base ART & $8(20.00)$ & $9(5.62)$ & $3.56(1.24-10.24)$ & 0.019 & $1.75(0.34-9.13)$ & 0.505 \\
\hline $\begin{array}{l}\text { Initiation } \mathrm{ART} \text { at } \mathrm{CD} 4+\text { count } \\
<350 \mathrm{cell} / \mu \mathrm{L}\end{array}$ & $29(72.5)$ & $77(48.13)$ & $2.84(1.33-6.08)$ & 0.007 & $31.36(6.5|-15| .22)$ & $<0.001$ \\
\hline $\begin{array}{l}\text { AIDS defining illness prior } \\
\text { ART }\end{array}$ & $17(42.5)$ & $33(20.75)$ & $2.82(1.35-5.88)$ & 0.006 & $0.99(0.2 I-4.7 I)$ & 0.985 \\
\hline
\end{tabular}

Abbreviations: AIDS, acquired immunodeficiency syndrome; ART, antiretroviral therapy; NNRTI, non-nucleoside reverse transcriptase inhibitor; PCP, pneumocystis pneumonia; PI, protease inhibitor.

the most appropriate prescription, preventing drug-to-drug interaction and increasing knowledge to improve attitudes of patients towards ART.

In our study, factors affecting virologic failure in firstline antiretroviral regimen were being female, younger age ( $\leq 40$ yrs.), CD $4+$ count $\leq 200$ cells $/ \mu \mathrm{L}$, TB and initiating ART at CD4+ count $\leq 350$ cell $/ \mu \mathrm{L}$. Similarly, one related study in Thailand demonstrated that poor adherence, a low CD4+ count at baseline $(<100$ cells $/ \mu \mathrm{L})$, and old age were the predictors for treatment failure. ${ }^{11}$ As well as some reports from Africa, virologic failure was associated with nonadherence to medications, age $>40$ years, a CD4 + count $<250$ cell $/ \mu$, tuberculosis and being male. ${ }^{14,15}$ Age and sex were found to be the predictors of virologic failure in several reports. However, the results were diverse in that being either male or female, and older or younger age correlated with virologic failure revealed different outcomes in each report. These might be explained by different geographic areas and socioeconomic statuses among studies. ${ }^{10,11,14,15}$

In 2015, one study described initiating antiretroviral therapy among HIV-positive adults with a CD4 + count of $>500$ cells $/ \mu \mathrm{L}$ provided net benefits over starting such therapy among patients after the CD4+ count had declined to 350 cells $/ \mu \mathrm{L} .{ }^{16}$ In our study, subjects presenting a CD4+ count $\leq 200$ cells $/ \mu \mathrm{L}$ were found to be 3.55 times higher at risk of virologic failure. Further, subjects initiating ART at CD4+ count $<350$ cell $/ \mu \mathrm{L}$ were found to be 31.36 times higher at risk of virologic failure. Due to the decline of HIV-1-specific CD4 $\mathrm{T}$ helper cells, qualitative impairments of CD4 T cell function and functional impairment of CD4 $\mathrm{T}$ cells indirectly led to functional impairment of HIV-1 specific CD8 T cells or B cell responses to control viral replication. ${ }^{17}$ Subsequently, the number of viruses in the body increased, possibly leading to virologic resistance. ${ }^{18}$ Early initiation of ART after diagnosis of HIV/AIDS regardless of CD4 + count level not only showed better outcome in reducing HIV/AIDS-related illness, but might reduce the risk of virologic failure.

Poor adherence was the major cause of virologic failure, similar to other reports. ${ }^{11,14,15}$ The remaining patients $(32.5 \%)$ presented good adherence regarding virologic failure, while all patients in the control group showed good adherence. In this study, adherence was measured by patient self-reporting and pill counts between visits without using a standardized questionnaire. The type of adherence measurement was debated concerning its reliability resulting in a discordance effect in some studies. ${ }^{19,20}$ Despite the reported good adherence in our cohort, virologic failure and acquired HIV drug resistance also occurred. Consequently, care plans should be developed to include reliable adherence measurements, for instance, a standardized questionnaire ${ }^{21,22}$ and electronically shared medical records. ${ }^{23}$

Females also faced increased risk of virologic failure in this cohort that might be explained by dependency status. From one related study featuring numerous female subjects, specific determinants of HIV virologic failure included lack of income, unemployment, dependent living situation and financial dependency. ${ }^{24}$ Similarly, younger 
age group ( $<40 \mathrm{yr}$.) also exhibited increased risk of virologic failure and was possibly related to maturity of life and disease-specific education which influenced long-term adherence and subsequently developed virologic failure. ${ }^{25,26}$

Interestingly, TB incidence was found to be 8.66 times higher among subjects at risk of virologic failure. TB was also described as the factor of either HIV virologic or immunologic failure. ${ }^{9,27,28}$ Several reasons can explain these phenomena, eg, M.tuberculosis induced apoptosis of CD4+ cells, subsequently leading to depletion of CD4 + cells, impairs cellular immune responses and results in immunologic failure. ${ }^{29}$ Furthermore, in treatment aspects of TB and HIV co-infection, antiretroviral and anti-TB constituted major obstacles for patients. Pill burden, adverse drug-to-drug interaction and unfavorable reactions of these drugs might have posed challenges leading to intolerance, poor adherence and subsequent virologic failure.

Surprisingly, the estimated prevalence of virologic failure in Phramongkutklao Hospital (5.34\%) was relatively low compared with related studies indicating it ranged from 4.1 to $14.7 \%{ }^{7,9}$ The observed variation may have been a result of different geographic areas, study settings, the endpoint of virologic failure and patient adherence. Nevertheless, the low prevalence of virologic failure in our cohort could be explained in that almost one half of participants were government officers having obtained high education level and stable life activities resulting in good adherence to their ART. ${ }^{9,30}$

In our urban HIV clinic, the strongest risk factors of virologic failure including delayed initiation of ART, opportunistic infections and low CD4 + count resembled those found in rural HIV clinics. ${ }^{31}$ Multisector strategies should be implemented to solve this problem. Improving public health policy focused on active HIV-positive case findings as well as early initiation of ART and linkage to care should be encouraged. ${ }^{32}$ Innovative HIV care models should be developed and assessed, eg, telemedicine and smartphone applications to enhance adherence which have been reported as acceptable by young PLWHA. ${ }^{33,34}$ Developing multidisciplinary comprehensive HIV care teams, to support patients as they experience the HIV continuum of care from diagnosis to viral suppression and retention in the system, should be warranted and initially target PLWHA presenting a high risk of HIV virologic failure. ${ }^{35}$

This study constituted a large urban HIV cohort assembled from 20 years' treatment experiences of PLWHA in a Thai university hospital and demonstrated the determinants of first-line antiretroviral failure in an urban HIV clinic setting exhibiting a low prevalence of HIV virologic failure and high education level of patients. Nevertheless, our study encountered several limitations. First, pretreatment HIV-viral loads were not performed among all patients, so we could not evaluate HIV-viral load level as a predictor of virologic failure. Second, adherence measurement and documentation were unstandardized. However, this represented usual clinical practices and adherence was and remained the strongest predictor for virologic failure. Third, we collected retrospective data; therefore, the accuracy of analysis depended on the completeness of data entry in the hospital database. Fourth, according to the low prevalence of HIV virologic failure in our cohort, the case control study was designed. Selection bias constituted a major concern, so we used a nested case control study to minimize this bias. Finally, this involved a limited single center experience. Thus, the less generalizable findings should be appraised and compared with other cohorts. A prospective multicenter study using standardized adherence measurement should be further investigated.

Despite these limitations, this study provided important information which would be useful for ART treatment programs in clinical practice especially in the urban HIV clinic setting.

\section{Conclusion}

Our study revealed that factors favoring virologic failure included CD4+ count $<200$ cells $/ \mu \mathrm{L}, \mathrm{TB}$ and starting ARV at $\mathrm{CD} 4+$ count $<350 \mathrm{cell} / \mu \mathrm{L}$. Integrative multisector strategies should be implemented including improving public health policy focused on active HIV-positive case findings, early initiation of ART and linkage to care, developing innovative HIV care models as well as setting up multidisciplinary comprehensive HIV care teams to support patients along the HIV continuum of care to prevent virologic failure and drug resistance, especially among patients initiating ART at low CD4+ counts and TB co-infection.

\section{Abbreviations}

AIDS, acquired immunodeficiency syndrome; ADI, AIDS defining illness; ART, antiretroviral therapy; ARV, antiretroviral; ATV/r, atazanavir/ritonavir; EFV, efavirenz; HIV, The human immunodeficiency viruses; LPV/r, lopinavir/ ritonavir; NRTI, nucleoside reverse transcriptase inhibitor; NNRTI, non-nucleoside reverse transcriptase inhibitor; NPV, nevirapine; OI, opportunistic infections; PCP, pneumocystis pneumonia; PI, protease inhibitor; PLWHA, 
people living with HIV/AIDS; RPV, rilpivirine; TB, tuberculosis.

\section{Acknowledgments}

We would like to express our gratitude to the personnel of the Network to Ending AIDS in Bangkok (NEAB) Project and Division of AIDS and STI, Department of Disease Control, Thai Ministry of Public Health, who provided insight and expertise that greatly assisted the research, although they may not agree with all of the interpretations of this paper.

\section{Author Contributions}

All authors made a significant contribution to the reported work, whether that was in the conception, study design, execution, acquisition of data, analysis and interpretation, or in all these areas; took part in drafting, revising or critically reviewing the article; provided final approval of the version to be published; agreed on the journal to which the article has been submitted and have agreed to be accountable for all aspects of the work.

\section{Funding}

This study was supported by the Division of Infectious Diseases, Department of Internal Medicine, Phramongkutklao Hospital. The funder supported budget during the patient data collection process and all research equipment expenses, eg, office supplies.

\section{Disclosure}

The authors declare they have no existing or potential conflict of interest relevant to this work.

\section{References}

1. Panel on antiretroviral guidelines for adults and adolescents: guidelines for the use of antiretroviral agents in adults and adolescents with HIV [Internet]. Department of Health and Human Services; 2020. Available from: http://aidsinfo.nih.gov/contentfiles/lvguidelines/ AdultandAdolescentGL.pdf. Accessed March 22, 2020.

2. d'Arminio Monforte A, Lepri AC, Rezza G, et al. Insights into the reasons for discontinuation of the first highly active antiretroviral therapy (HAART) regimen in a cohort of antiretroviral naïve patients. I.CO.N.A. Study Group. Italian cohort of antiretroviral-naïve patients. AIDS. 2000;14(5):499-507. doi:10.1097/00002030-200003310-00005

3. Mocroft A, Youle M, Moore A, et al. Reasons for modification and discontinuation of antiretrovirals: results from a single treatment centre. AIDS. 2001;15(2):185-194. doi:10.1097/00002030200101260-00007

4. Paredes R, Lalama CM, Ribaudo HJ, et al. Pre-existing minority drug-resistant HIV-1 variants, adherence, and risk of antiretroviral treatment failure. J Infect Dis. 2010;201(5):662-671. doi:10.1086/650543
5. Chasombat S, McConnell MS, Siangphoe U, et al. National expansion of antiretroviral treatment in Thailand, 2000-2007: program scale-up and patient outcomes. J Acquir Immune Defic Syndr. 2009;50(5):506-512. doi:10.1097/QAI.0b013e3181967602

6. Thailand National Guidelines on HIV/AIDS Treatment and Prevention 2017 [Internet]; 2017. Available from: http://www. thaiaidssociety.org. Accessed March 22, 2020.

7. Ayalew MB, Kumilachew D, Belay A, et al. First-line antiretroviral treatment failure and associated factors in HIV patients at the University of Gondar Teaching Hospital, Gondar, Northwest Ethiopia. HIV AIDS. 2016;8:141-146. doi:10.2147/HIV.S112048

8. Robbins GK, Daniels B, Zheng H, Chueh H, Meigs JB, Freedberg KA. Predictors of antiretroviral treatment failure in an urban HIV clinic. J Acquir Immune Defic Syndr. 2007;44(1):30-37. doi:10.1097/01.qai.0000248351.10383.b7

9. Ayele G, Tessema B, Amsalu A, Ferede G, Yismaw G. Prevalence and associated factors of treatment failure among HIV/AIDS patients on HAART attending University of Gondar Referral Hospital Northwest Ethiopia. BMC Immunol. 2018;19(1):37. doi:10.1186/ s12865-018-0278-4

10. Hassan AS, Nabwera HM, Mwaringa SM, et al. HIV-1 virologic failure and acquired drug resistance among first-line antiretroviral experienced adults at a rural HIV clinic in coastal Kenya: a cross-sectional study. AIDS Res Ther. 2014;11(1):9. doi:10.1186/1742-6405-11-9

11. Khienprasit N, Chaiwarith R, Sirisanthana T, Supparatpinyo K. Incidence and risk factors of antiretroviral treatment failure in treatment-naïve HIV-infected patients at Chiang Mai University Hospital, Thailand. AIDS Res Ther. 2011;8(1):42. doi:10.1186/1742-6405-8-42

12. WHO Guideline Review committee. Consolidated guidelines on the use of antiretroviral drugs for treating and preventing HIV infection: recommendations for public health approach [Internet]. World Health Organization; 2013. Available from: https://www.who.int/hiv/pub/ arv/arv-2016/en/. Accessed march 22, 2020.

13. Sidibé M, Loures L, Samb B. The UNAIDS 90-90-90 target: a clear choice for ending AIDS and for sustainable health and development. J Int AIDS Soc. 2016;19.

14. Bulage L, Ssewanyana I, Nankabirwa V, et al. Factors associated with virological non-suppression among HIV-positive patients on antiretroviral therapy in Uganda, August 2014-July 2015. BMC Infect Dis. $2017 ; 17$.

15. Hailu GG, Hagos DG, Hagos AK, Wasihun AG, Dejene TA. Virological and immunological failure of HAART and associated risk factors among adults and adolescents in the Tigray region of Northern Ethiopia. PLoS One. 2018;13(5):e0196259. doi:10.1371/ journal.pone. 0196259

16. Group TISS. Initiation of antiretroviral therapy in early asymptomatic HIV infection. $N$ Engl J Med. 2015;373(9):795-807. doi:10.1056/ NEJMoa1506816

17. Ahmed T, Borthwick NJ, Gilmour J, Hayes P, Dorrell L, Hanke T. Control of HIV-1 replication in vitro by vaccine-induced human CD8 (+) T cells through conserved subdominant Pol epitopes. Vaccine. 2016;34(9):1215-1224. doi:10.1016/j.vaccine.2015.12.021

18. Lindqvist M, van Lunzen J, Soghoian DZ, et al. Expansion of HIV-specific $\mathrm{T}$ follicular helper cells in chronic HIV infection. J Clin Invest. 2012;122(9):3271-3280. doi:10.1172/JCI64314

19. Perno CF, Ceccherini-Silberstein F, De Luca A, et al. Virologic correlates of adherence to antiretroviral medications and therapeutic failure. J Acquir Immune Defic Syndr. 2002;31(Suppl 3):S118-22. doi:10.1097/00126334-200212153-00006

20. Turner BJ. Adherence to antiretroviral therapy by human immunodeficiency virus-infected patients. J Infect Dis. 2002;185(s2):S143S51. doi:10.1086/340197

21. Vriesendorp R, Cohen A, Kristanto P, et al. Adherence to HAART therapy measured by electronic monitoring in newly diagnosed HIV patients in Botswana. Eur $J$ Clin Pharmacol. 2007;63 (12):1115-1121. doi:10.1007/s00228-007-0369-2 
22. Segeral O, Madec Y, Ban B, et al. Simplified assessment of antiretroviral adherence and prediction of virological efficacy in HIV-infected patients in cambodia. AIDS Res Treat. 2010;2010:142076. doi:10.1155/2010/142076

23. Saberi P, Catz SL, Leyden WA, et al. Antiretroviral therapy adherence and use of an electronic shared medical record among people living with HIV. AIDS Behav. 2015;19(Suppl 2(0 2)):177-185. doi:10.1007/s10461-014-0982-x

24. Hare AQ, Ordóñez CE, Johnson BA, et al. Gender-specific risk factors for virologic failure in KwaZulu-Natal: automobile ownership and financial insecurity. AIDS Behav. 2014;18(11):2219-2229. doi:10.1007/s10461-014-0849-1

25. Lucas GM, Chaisson RE, Moore RD. Highly active antiretroviral therapy in a large urban clinic: risk factors for virologic failure and adverse drug reactions. Ann Intern Med. 1999;131(2):81-87. doi:10.7326/0003-4819-131-2-199907200-00002

26. Mujugira A, Celum C, Tappero JW, Ronald A, Mugo N, Baeten JM. Younger age predicts failure to achieve viral suppression and virologic rebound among HIV-1-infected persons in serodiscordant partnerships. AIDS Res Hum Retroviruses. 2016;32(2):148-154. doi:10.1089/aid.2015.0296

27. Zeleke A. Prevalence of antiretroviral treatment failure and associated factors in HIV infected children on antiretroviral therapy at Gondar University Hospital, retrospective cohort study. Int $\mathrm{J}$ Med Med Sci. 2016;8(11):125-132.

28. Musa BM, Musa B, Muhammed H, Ibrahim N, Musa AG. Incidence of tuberculosis and immunological profile of TB/HIV co-infected patients in Nigeria. Ann Thorac Med. 2015;10(3):185-192. doi:10.4103/1817-1737.160838
29. Zhang Q, Sugawara I. Immunology of tuberculosis. World J Exp Med. 2012;2(4):70-74. doi:10.5493/wjem.v2.i4.70

30. Yuan D, Liu M, Jia P, et al. Prevalence and determinants of virological failure, genetic diversity and drug resistance among people living with HIV in a minority area in China: a population-based study. BMC Infect Dis. 2020;20(1):443. doi:10.1186/s12879-020-05124-1

31. Liégeois F, Vella C, Eymard-Duvernay S, et al. Virological failure rates and HIV-1 drug resistance patterns in patients on first-line antiretroviral treatment in semirural and rural Gabon. $J$ Int AIDS Soc. 2012;15(2):17985. doi:10.7448/IAS.15.2.17985

32. Penda CI, Moukoko CEE, Koum DK, et al. Feasibility and utility of active case finding of HIV-infected children and adolescents by provider-initiated testing and counselling: evidence from the Laquintinie hospital in Douala, Cameroon. BMC Pediatr. 2018;18 (1):259. doi:10.1186/s12887-018-1235-3

33. Muessig KE, Nekkanti M, Bauermeister J, Bull S, Hightow-Weidman LB. A systematic review of recent smartphone, Internet and Web 2.0 interventions to address the HIV continuum of care. Curr HIV/AIDS Rep. 2015;12(1):173-190. doi:10.1007/s11904-014-0239-3

34. Hightow-Weidman LB, Muessig KE, Bauermeister J, Zhang C, LeGrand S. Youth, technology, and HIV: recent advances and future directions. Curr HIV/AIDS Rep. 2015;12(4):500-515. doi:10.1007/ s11904-015-0280-x

35. Elgalib A, Al-Sawafi H, Kamble B, Al-Harthy S, Al-Sariri Q. Multidisciplinary care model for HIV improves treatment outcome: a single-centre experience from the Middle East. AIDS Care. 2018;30 (9):1114-1119. doi:10.1080/09540121.2018.1479028

\section{Publish your work in this journal}

HIV/AIDS - Research and Palliative Care is an international, peerreviewed open-access journal focusing on advances in research in HIV, its clinical progression and management options including antiviral treatment, palliative care and public healthcare policies to control viral spread. The manuscript management system is completely online and includes a very quick and fair peer-review system, which is all easy to use. Visit http://www.dovepress.com/testimonials.php to read real quotes from published authors. 